\title{
Análise da taxa SELIC, PIB E Inflação no Brasil, no período de 2007 a 2016
}

Analysis of SELIC rate, GDP and Inflation in Brazil, from 2007 to 2016

Nilson Gonçalves ${ }^{1}$; Leandro Meira²; Gisele Gusmão ${ }^{3}$; Tand Cordeiro ${ }^{4}$; Claudinel Dias ${ }^{5}$.

${ }^{1}$ E-mail: n.juneo@homail.com

Universidade Estadual de Montes Claros (UNIMONTES)

\section{${ }^{2}$ UNIMONTES \\ ${ }^{3}$ Universidade Federal de Viçosa (UFV);} UNIMONTES.

${ }^{4}$ UNIMONTES

${ }^{5}$ UNIMONTES

\begin{abstract}
Resumo: No presente artigo busca-se identificar uma relação entre mudanças na taxa básica de juros (SELIC), no Brasil, sobre a inflação e o PIB, bem como o grau dessa relação. No contexto da política monetária, entende-se que uma redução da taxa de juros implica um aumento da atividade produtiva e, por outro lado, uma tendência a um aumento na inflação. Para responder a essa questão, utilizouse além de análise descritiva, o coeficiente linear de Pearson que mede o grau de relação entre as variáveis em estudo. Logo, conclui-se que a variação na taxa de juros possui maior relação sobre o PIB e menor relação com a inflação.
\end{abstract}

Palavras-chave: Taxa SELIC; PIB; Inflação.

\begin{abstract}
This article aims to identify a relation between changes in the base interest rate (SELIC), in Brazil, on inflation and GDP (Gross Domestic Product), as well as the degree of this relation. In monetary policy context, it is understood that a reduction in the interest rate implies an increase in productive activity and, on the other hand, a tendency towards an increase in inflation. In order to answer this question, Pearson's linear coefficient, which measures the degree of relationship between the variables under study, was used in addition to descriptive analysis. Therefore, it can be concluded that the variation in the interest rate has a greater relation to GDP and a lower relation with inflation.
\end{abstract}

Keywords: SELIC rate, GDP, Inflation. 


\section{INTRODUÇÃO}

No Brasil, o principal mecanismo de controlo inflacionário utilizado pelas autoridades monetárias é a taxa de juros. Esse mecanismo tornou-se ainda mais importante, a partir de junho de 1999, quando foi adotado no Brasil o sistema de metas inflacionárias, que já vinha sendo adotado na maioria dos países da América Latina. A partir de então, ficou claro que a preocupação primordial da política económica deveria ser o alcance das metas estabelecidas (LEITE; ALMEIDA, 2012).

A taxa básica de juros, SELIC ${ }^{1}$, é uma espécie de teto para os juros pagos pelos bancos nos depósitos a prazo. A partir dela, os bancos também definem qual a taxa que vão cobrar de quem procura por empréstimos. Esta taxa é usada para operações de curtíssimo prazo entre os bancos, que, quando querem tomar recursos emprestados de outros bancos por um dia, oferecem títulos públicos como lastro, visando reduzir o risco e, consequentemente, a remuneração da transação (BCB, 2007).

As decisões do Comité de Política Monetária (Copom) sobre a taxa de juros SELIC têm sido acompanhadas por diversas instituições e analistas financeiros, agentes económicos, académicos, políticos etc. com o intuito de entender e prever possíveis movimentos na taxa de juros. O Copom é o órgão decisório da política monetária do Banco Central do Brasil e o responsável por definir a meta para a taxa Selic, tendo sido instituído em 20 de junho de 1996 (CAETANO; SILVA JR; CORRÊA, 2011).

A SELIC é utilizada também para estipular o valor do capital nas operações de mercado aberto com títulos públicos (open market). Nessas operações, a taxa média de um dia é denominada no mercado por Taxa Média Selic (TMS). Além disso, é denominada uma taxa "over" adequada para dias úteis e determinadas para operações com títulos públicos de emissão do Governo Federal (ASSAF NETO, 2006).

A importância da definição da taxa de juros pelo BCB (Banco Central do Brasil) é a capacidade que essa variável possui para influenciar o comportamento do nível de preços e a atividade da economia (MENDOÇA, 2005). Em outras palavras, Muniz et al. (2012) descreve que é através da SELIC que o Banco Central controla o nível de preços

\footnotetext{
${ }^{1}$ SELIC - Sistema Especial de Liquidação e Custódia.

$\mathrm{e}^{3}$ - Revista de Economia, Empresas e Empreendedores na CPLP | Volume 3 | Número 2
} 


\section{pontěditora}

e ajusta o grau de demanda agregada. Conforme Mendonça (2005), deve-se destacar que é através da taxa SELIC que as demais taxas, por mediação, são determinadas.

Segundo Machado e Pontili (2008), a taxa de juros é alterada através de decisões com o objetivo de cumprir as metas de inflação, que também são estabelecidas pelo Banco Central. De acordo com Carvalho e Silva (2008, p.15), "a taxa Selic é ajustada frequentemente para que os preços tendam para o objetivo da inflação estabelecida”.

Sabe-se que a elevação da taxa de juros gera a diminuição do consumo e do investimento, como consequência ocasiona a diminuição dos preços dos produtos o que causa queda nos índices de inflação. Dessa forma, a SELIC é utilizada pelo governo como mecanismo monetário para combater a inflação (LIMA, 2015).

No Brasil, a inflação surgiu por meio de uma acelerada expansão do crédito. Cronistas, economistas e historiadores relatam o início da explosão inflacionária no final do século XIX, o qual passou a ganhar destaque durante a década de 1980 (CARDOSO, 2007, p. 95).

Para Lopes e Rossetti (2001, p. 303)

[...] a inflação é caracterizada por um aumento no nível geral de preços. Mas para ser característica típica da inflação, o aumento precisa alcançar todas as camadas e conjuntos de fatores de produção e de bens e serviços finais movimentadas na economia. Por causa do efeito generalizado do aumento de preços, a elaboração de índices que servem como indicação da inflação.

O IPCA (Índice Nacional de Preços ao Consumidor Amplo) é o índice mais importante do ponto de vista da política económica. Além de ser, segundo Oliveira et al. (2011), medidor oficial da inflação no país, foi determinado pelo Conselho Monetário Nacional como parâmetro para o sistema de metas de inflação implementado no Brasil em 1999.

O IPCA é o índice de preços oficial definido pelo Conselho Monetário Nacional para o regime de metas, para a inflação é o IPCA disponibilizado pelo IBGE. O IPCA mede a variação de preços nos bens consumidos por famílias com renda de 1 a 40 salários mínimos, em nove regiões metropolitanas (Belém, Belo Horizonte, Curitiba, Fortaleza, Porto Alegre, Recife, Rio de Janeiro, Salvador e São Paulo), no Distrito Federal e no município de Goiânia. O IPCA é um índice de Laspeyres que calcula a 


\section{pontěditora}

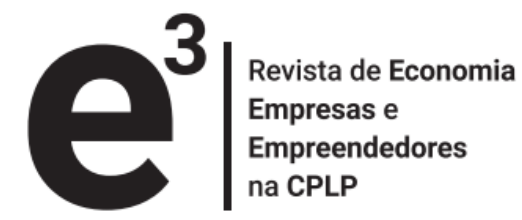

variação dos preços de bens e serviços entre dois períodos (comparação dos preços vigentes nos trinta dias do período de referência e com os trinta dias do período base), ponderando a participação dos gastos com cada bem no consumo total (MENDONÇA, 2007).

No cenário económico brasileiro, o regime de metas de inflação foi implementado de acordo com as características macroeconómicas do país aquando da implementação em meados de 1999, no que diz respeito à escolha das metas, dos intervalos de variação e do índice que mediria a inflação. Esse processo e os debates que foram surgindo ao longo do mesmo serão expostos por esse trabalho, que apresentará em sua última secção uma explicação teórica e empírica mais detalhada de um dos motivos de grande discussão entre os proponentes do regime de metas inflacionárias e seus críticos, que é a escolha do Índice de Preços ao Consumidor Amplo (IPCA) como balizador da inflação (CARRARA; CORREA, 2012).

A política monetária é implementada levando em conta a inflação medida pelo Índice Nacional de Preços ao Consumidor Amplo (IPCA) cheio. Como forma de flexibilizar a estratégia monetária adotada, foram definidos intervalos de tolerância para a inflação (MENDONÇA, 2007).

Um ponto de grande importância para a análise do regime de metas para inflação advém do facto de o IPCA ser muito sensível aos reajustes nos preços administrados por contratos e monitorados (que dependem da autorização prévia do governo ou de algum órgão do poder público). Devido à alteração da estrutura do IPCA, em agosto de 1999, os preços administrados passaram a ter um peso que corresponde a $28,7 \%$ na sua composição (MENDONÇA, 2007).

É notório o argumento de que o BCB utiliza a taxa SELIC como principal instrumento para o controlo da inflação. Entretanto, uma parte não desprezível da inflação medida pelo IPCA não é sensível à taxa SELIC, uma vez que os preços administrados são, em sua maioria, determinados por contratos e dependem da observação da inflação passada medida por IGPs (Índice Geral de Preços). Logo, a taxa de juros não estaria sendo utilizada de forma adequada. A sua aplicação correta deveria levar em conta pressões de demanda que levam a elevações nos preços livres. A 


\section{pontěditora}

resposta da taxa de juros à inflação dos preços livres e à inflação dos preços administrados é analisada sob uma perspectiva econométrica na secção a seguir (MENDONÇA, 2007).

A dinâmica da função de reação do Banco Central do Brasil indica que a taxa SELIC reage às variações da taxa nominal de câmbio, as quais são o principal determinante da variação do IPCA. Dessa forma, o BCB termina por elevar a taxa de juros básica para combater pressões inflacionárias que não advêm necessariamente do lado da demanda da economia, mas que são causadas frequentemente pelas pressões de custo oriundas dos efeitos da desvalorização cambial sobre o custo de produção das firmas. Como a inflação brasileira é predominantemente uma inflação de custos, a política monetária só pode ter impacto sobre a taxa de inflação por intermédio de aumentos significativos da taxa básica de juros (OREIRO, PAULA; AMARAL, 2012).

O PIB (Produto Interno Bruto) é um dos principais indicadores de uma economia. Ele demonstra o valor de toda a riqueza gerada no país, sendo o conjunto de todos os bens e serviços finais produzidos num país durante certo período de tempo. $\mathrm{O}$ PIB só leva em conta para cálculo, os bens e serviços finais, para não calcular o mesmo item mais de uma vez (IBGE, 2007).

Mankiw (2013, p. 468) define o PIB como um "valor de mercado de todos os bens e serviços finais produzidos em um país em dado período". Para o autor, o PIB é determinado pelo total da renda de todas as pessoas da economia e pelo total de despesa com bens e serviços que foram produzidos na economia (MANKIW, 2013, p. 466). Já para Assaf Neto (2009, p.6), “o Produto Interno Bruto de uma economia equivale ao valor, a preços de mercado, dos bens e serviços realizados em um país em certo período de tempo".

Esse custo de se combater a inflação surge porque os preços administrados, que representam 29,5\% do IPCA, apresentam constantemente uma tendência de crescimento maior do que a dos preços livres, o que acaba aumentando a parcela da inflação captada pelo IPCA insensível a aumentos na taxa de juros. Sendo assim, os formuladores de política são obrigados a elevar a um nível mais alto os juros (SELIC) para reprimir excessivamente os preços livres, de forma a compensar a forte pressão exercida pelos 


\section{pontěditora}

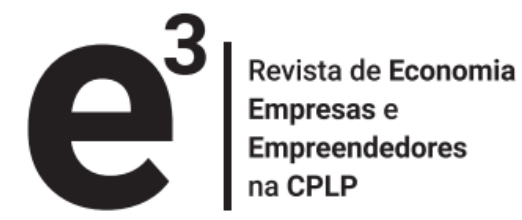

preços monitorados. Mantém-se, assim, a SELIC num nível superior àquele que seria necessário se todos os preços fossem livres. Em consequência dos juros elevados, a demanda agregada é reprimida, o que, por sua vez, acaba gerando redução da taxa de crescimento económico e um possível aumento da dívida pública, já que a mesma é vinculada à SELIC (CARRARA; CORREA, 2012).

Durante a década analisada, entre 2007 a 2016, o PIB manteve um considerável crescimento desde 2007 até 2008, quando começou a cair. Vale ressaltar que em 2008 e 2009 a economia mundial foi abalada pela crise ocorrida nos Estados Unidos, o que pode ter influenciado o PIB brasileiro. O PIB brasileiro teve o seu pico nessa década em 2010 e, após esse ano, em 2012 começou a decrescer até chegar ao ano de 2014 com taxas negativas.

Desta forma, busca-se no presente artigo identificar a correlação entre a taxa de juros básica da economia brasileira (SELIC), com o nível da atividade económica do país (PIB), e com a inflação (IPCA). Questiona-se o grau de influência da política monetária, em especial, da taxa de juros básica da economia sobre o nível da atividade produtiva e sobre a inflação.

\section{MÉTODO}

Além de uma análise descritiva, que segundo Santos (1999) trata-se de um levantamento das características conhecidas que são componentes do facto, do problema ou do fenómeno em estudo, busca-se identificar o grau de correlação entre a taxa básica de juros, a inflação e a variação do PIB, entre 2007 e 2016, por meio do coeficiente de correlação linear de Pearson.

O coeficiente de correlação linear de Pearson não diferencia entre as variáveis dependentes e independentes, ou seja, o grau de correlação entre X e Y é o mesmo que entre Y e X, portanto a correlação não se aplica à distinção de causalidade simples ou recursiva (SCHIELD, 1995).

É importante também descrever o caráter adimensional do coeficiente. Não faz sentido interpretar uma correlação de 0,2 como $20 \%$, pois também este valor não se 


\section{pontěditora}

refere à proporção, por exemplo, uma correlação de 0,2 não pode ser interpretada como o dobro de 0,1 (CHEN; POPOVIC, 2000).

Outra hipótese é de que as duas variáveis tenham distribuição normal bivariada conjunta, ou seja, para cada $\mathrm{X}$ dado como variável $\mathrm{Y}$ é normalmente distribuída (SNEDECOR; COCHRAN, 1980).

$\mathrm{Na}$ prática o coeficiente (r) é interpretado como um indicador que descreve a interdependência entre as variáveis $\mathrm{X}$ e Y. A interpretação para $\mathrm{r}=1$ é de que existe correlação linear perfeita entre as variáveis X e Y. Logo, para $r=-1$ tem-se correlação linear perfeita negativa. E para $r=0$, não existe correlação linear entre as variáveis $\mathrm{X}$ e Y. Mas valores extremos, como 0 e 1, dificilmente são encontrados na prática.

Desta forma, o coeficiente de correlação, segundo Callegari-Jacques (2003), pode ser avaliado qualitativamente da seguinte maneira: i) se $0,00<|r|<0,30$, existe fraca correlação linear; ii) se $0,30<|r|<0,60$, existe moderada correlação linear; iii) se $0,60<|r|<0,90$, existe forte correlação linear; e, iv) se $0,90<|r|<1,00$, existe correlação linear muito forte.

\section{Fonte e tratamento dos dados}

Como visto na secção anterior, para que se possa realizar o teste de correlação de Pearson, antes é necessário verificar se as séries em estudo apresentam distribuição normal.

A maior parte das estatísticas foi construída sob a hipótese de normalidade. Por tal razão, é imprescindível a existência de um teste para testar a normalidade de um conjunto de dados (THODE JR, 2002). Os testes de normalidades são empregados para verificar a distribuição normal de dados. Para este estudo será aplicado o teste de normalidade Shapiro-Wilk para as séries da variação percentual trimestral do PIB, para a taxa trimestral acumulada da inflação e para a média trimestral da taxa SELIC, entre 2007 e 2016.

Para a realização do teste de correlação foram coletadas as séries da variação percentual do PIB, a taxa SELIC e a inflação. De acordo com Gujarati (2000), os dados 


\section{pontěditora}

podem ser coletados em intervalos de tempo regulares, podendo estes serem diários, semanais, mensais, anuais entre outros. Neste caso, as séries serão trimestrais. Os dados da taxa SELIC foram coletados no site do Banco Central do Brasil, que são uma média do trimestre calculada com os valores diários referentes à taxa de juros, os dados da inflação são o acumulado trimestral e foram coletados no site do IPEA, e os dados da variação percentual trimestral do PIB foram coletados no site do IBGE.

Ressalta-se que será considerado para os testes estatísticos um nível de significância de 0,05 (ou 5\%) e para a realização dos testes será utilizado o software Stata.

\section{RESULTADOS E DISCUSSÃO}

A evolução percentual trimestral do PIB brasileiro entre os anos de 2007 a 2016 é apresentada na figura 1. No Brasil, vários factores influenciam o PIB, dentre eles, estão o consumo, tanto pelo governo como pelas famílias, o investimento privado e público e as exportações líquidas. Os cálculos do PIB são feitos e divulgados pelo Instituto Brasileiro de Geografia e Estatística - IBGE.

Figura 1 - Evolução da variação trimestral do PIB, entre 2007 e 2016

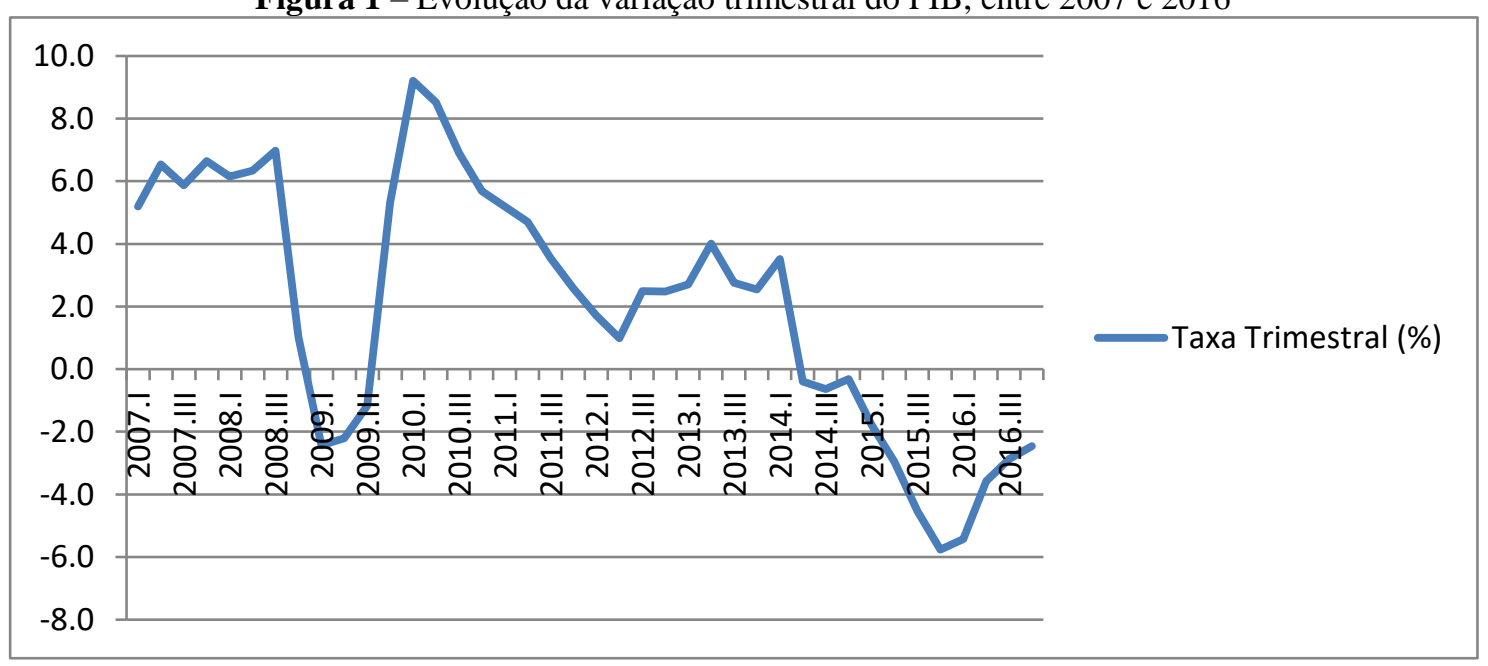

Fonte: Elaborado pelos próprios autores com base nos dados do IBGE (2017). 


\section{pontěditora}

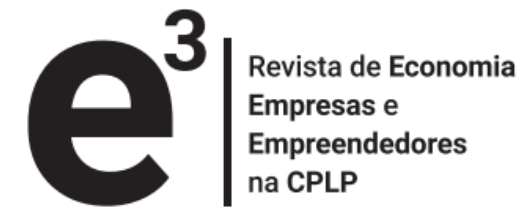

Como demonstra a Figura 1, a variação do PIB manteve-se num considerável crescimento desde 2007 até o segundo trimestre de 2008, quando começou a cair. Vale ressaltar que em 2008 e 2009 a economia mundial foi abalada pela crise ocorrida nos Estados Unidos, o que pode ter influenciado o PIB brasileiro.

Após o período de crise, o PIB brasileiro voltou a ter uma variação trimestral positiva, isto é, $9,2 \%$ no primeiro trimestre de 2010 , destacando-se com o maior valor da série analisada.

O Brasil continuou com taxas de variação positivas a partir de 2010. No entanto, houve uma tendência decrescente até o ano de 2012. A partir do segundo trimestre de 2014, a variação percentual do PIB começa a apresentar taxas negativas o que dura até o final de 2016.

A inflação é o aumento persistente dos preços, em geral, que leva a uma contínua perda de poder aquisitivo da moeda. A inflação possui vários índices, entre eles, o IGP (Índice Geral de Preços), IPA (Índice de Preços no Atacado), INPC (Índice nacional de Preços ao Consumidor) e o IPCA, que é o analisado no estudo (SANDRONI, 2003).

O IPCA também é calculado pelo IBGE e, conforme o BACEN, mede a variação dos custos dos gastos das famílias, no período do primeiro ao último dia de cada mês de referência, com alimentação, transporte, vestuário, etc.

O acumulado trimestral da inflação no Brasil, conforme a Figura 2, apresenta grandes oscilações no decorrer do período analisado, atingindo uma variação de 3,83\% no primeiro trimestre de 2015, alcançando uma inflação anual de $10,67 \%$, segundo o BACEN (2011), ultrapassando o teto da meta para o ano, que é definida pelo Conselho Monetário Nacional (CMN) e que para aquele ano era de 6,5\%.

$\mathrm{e}^{3}$ - Revista de Economia, Empresas e Empreendedores na CPLP | Volume 3 | Número 2 


\section{pontěditora}

Figura 2 - Evolução da variação trimestral acumulada do IPCA, entre 2007 a 2016

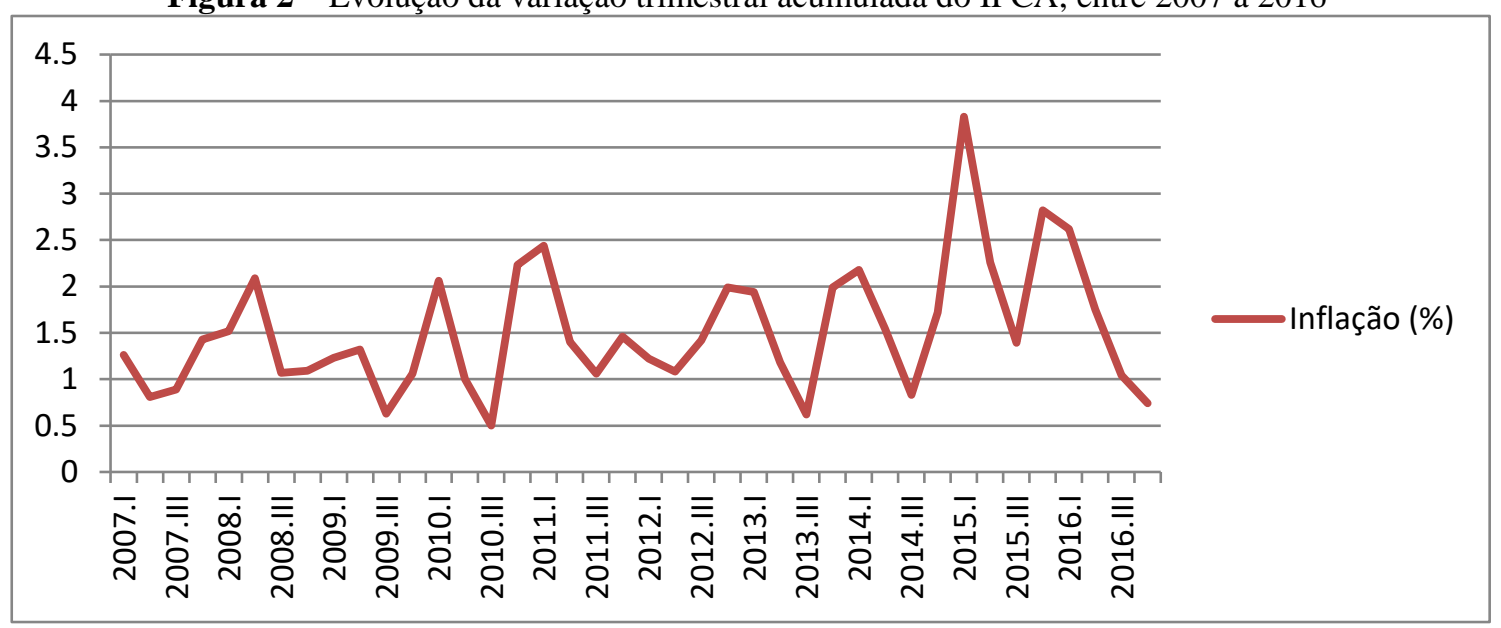

Fonte: Elaborado pelos próprios autores com base nos dados do IPEADATA (2017)

A taxa SELIC, como dito, é definida como a taxa média ajustada dos financiamentos diários apurados no Sistema Especial de Liquidação e de Custódia para títulos federais. Ela é considerada a taxa básica de juros da economia e é usada nos empréstimos feitos entre bancos e também nas aplicações feitas por essas instituições bancárias em títulos públicos.

Definida em reuniões pelo COPOM, a meta da taxa SELIC ao ano é usada como estímulo para quem deseja realizar aplicações financeiras atreladas a essa taxa. Para o ano de 2017, a meta da taxa SELIC foi fixada, até então, em 12,25\% a.a.

A taxa SELIC é calculada diariamente e pode ser apresentada em mensal e em taxa anual. Neste artigo, como já foi citado, usaremos uma média trimestral das taxas diárias da SELIC. O resultado dessa média, para o período analisado, esta apresentada na Figura 3. 


\section{pontěditora}

Figura 3 - Evolução da variação trimestral da taxa SELIC, entre 2007 e 2016

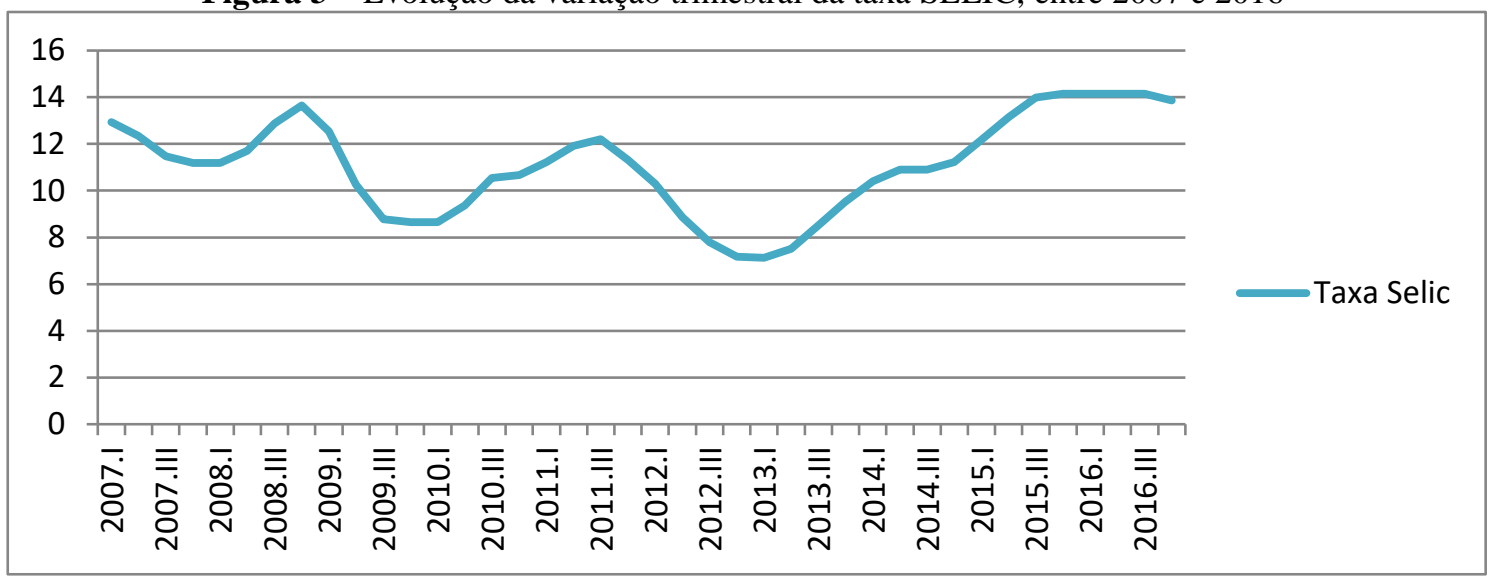

Fonte: Elaborado pelos próprios autores com base nos dados do BACEN (2017).

No período analisado nota-se que a taxa SELIC sofre oscilações desde 2007 até o segundo trimestre de 2015, entre crescimentos e declínios, quando ela se aproxima bem próxima da taxa de $14 \%$ e mantém este nível ate o final do período analisado.

As reuniões ordinárias do COPOM, para definir a meta da taxa SELIC, ocorrem aproximadamente a cada 45 dias. Nessas reuniões é apresentada a conjuntura económica atual e o cenário básico do COPOM. Após discussões acerca da condução da politica monetária, é definida a meta da taxa SELIC, sempre com uma justificativa para o aumento ou redução da meta. Segundo o Conselho de Políticas Monetárias, que baixou a meta em sua última reunião no ano de 2016, ocorrida nos dias 29 e 30 de novembro, a decisão por baixar a meta foi porque a atividade económica estava abaixo do que era esperado.

\section{Análise do Coeficiente de Correlação Linear de Pearson: testando a normalidade das séries}

Como descrito na metodologia, para realizar o teste de correlação de Pearson é necessário que os dados estejam normalmente distribuídos, impedindo que ocorra viés no resultado. Portanto, realizou-se o teste de normalidade Shapiro-Wilk para detectarmos as séries assimétricas no modelo, a partir do comando "swilk" no Stata, seguido de todas as variáveis. A Tabela 1 apresenta as séries em estudo e seus respectivos p-valores. 
ponteditiora $\quad \mathbf{e}^{3} \mid=$

Tabela 1 - Teste de Normalidade Shapiro-Wilk.

\begin{tabular}{r|cccrr}
\multicolumn{7}{c}{ Shapiro-Wilk W test for normal data } \\
Variable & Obs & W & V & z & Prob>z \\
\hline variaçãodo b & 40 & 0.96085 & 1.547 & 0.919 & 0.17913 \\
inflaçẫo & 40 & 0.92642 & 2.908 & 2.247 & 0.01233 \\
selic & 40 & 0.97941 & 0.814 & -0.434 & 0.66768
\end{tabular}

Fonte: Resultados da pesquisa

Considerando $\mathrm{H}_{0}$ a hipótese nula de distribuição normal da série, e $\mathrm{H}_{1}$ a hipótese alternativa de não normalidade e considerando nível de significância de 5\%, apenas as séries "variaçãodopib" e "selic" apresentaram distribuição normal (p-valor > 0,05), fazendo-se necessário a correção da outra série. Para realizar a correção da série foi preciso utilizar o comando "ladder" seguido do nome da variável. O resultado é apresentado abaixo na Tabela 2.

Tabela 2 - Correção da série inflação

\begin{tabular}{llrl} 
Transformation & formula & chi2(2) & P(chi2) \\
\hline cubic & inflação 3 & 43.04 & 0.000 \\
square & inflaçãon2 & 28.45 & 0.000 \\
identity & inflação & 9.79 & 0.007 \\
square root & sqrt(inflação) & 2.44 & 0.295 \\
log & log(inflação) & 0.06 & 0.972 \\
1/(square root) & 1/sqrt(inflação) & 3.94 & 0.139 \\
inverse & 1/inflação & 10.62 & 0.005 \\
1/square & 1/(inflaçãon2) & 25.52 & 0.000 \\
1/cubic & 1/(inflação 3) & 36.86 & 0.000
\end{tabular}

Fonte: Resultados da pesquisa

Verifica-se que, ao considerarmos um nível de significância de 0,05 (ou 5\%), três transformações normalizam a série, são elas: "sqrt(inflação)", "log(inflação)" e “1/sqrt(inflação)". No entanto, a transformação logarítmica aponta o melhor resultado e, portanto, a escolhida.

$\mathrm{e}^{3}$ - Revista de Economia, Empresas e Empreendedores na CPLP | Volume 3 | Número 2 


\section{pontěditora}

O comando "gladder inflação" mostra os histogramas de cada resultado e confirma se a referida série for transformada em logaritmo, ela atinge a normalidade (Figura 1).

Figura 1 - Histograma com os resultados da transformação da série "inflação".
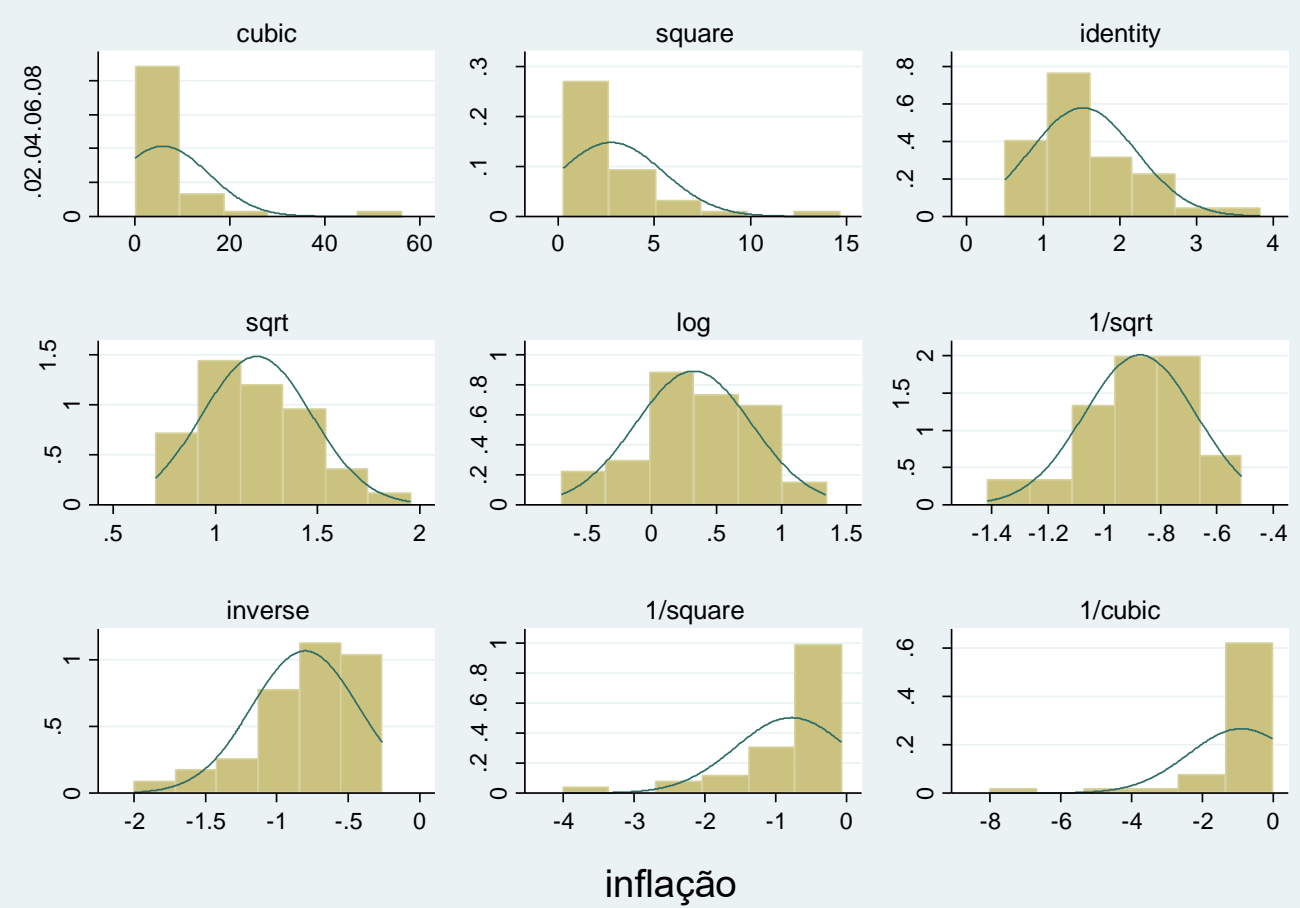

Histograms by transformation

Fonte: Resultados da pesquisa.

Aplicando-se novamente o teste $S W$ para a série transformada por meio do comando "swilk lninflação", confirma-se a sua normalidade (p-valor >0,05).

Tabela 3 - Aplicação do teste Shapiro-Wilk para a nova série transformada

\begin{tabular}{r|ccccc}
\multicolumn{7}{c}{ Shapiro-Wilk W test for normal data } \\
Variable & Obs & W & V & z & Prob>z \\
\hline lninflação & 40 & 0.99084 & 0.362 & -2.137 & 0.98372
\end{tabular}

Fonte: Resultados da pesquisa 


\section{pontěditora}

Uma vez que as séries foram normalizadas estão prontas para a realização do teste de correlação de Pearson.

\section{Resultado do Coeficiente de Correlação de Pearson}

Após realizar a correção das séries, já se pode aplicar o teste de Correlação de Pearson, já que as séries agora apresentam distribuição normal. Para aplicação do teste foi utilizado também o programa Stata, através do comando "corr" seguido das variáveis "selic", "Ininflação" e "variaçãodopib", já que o objetivo do teste é analisar a correlação existente entre a taxa SELIC e as demais variáveis.

O teste de Pearson apresentou os seguintes resultados (Tabela 4):

Tabela 4: Coeficientes do Teste de Correlação de Pearson para as variáveis

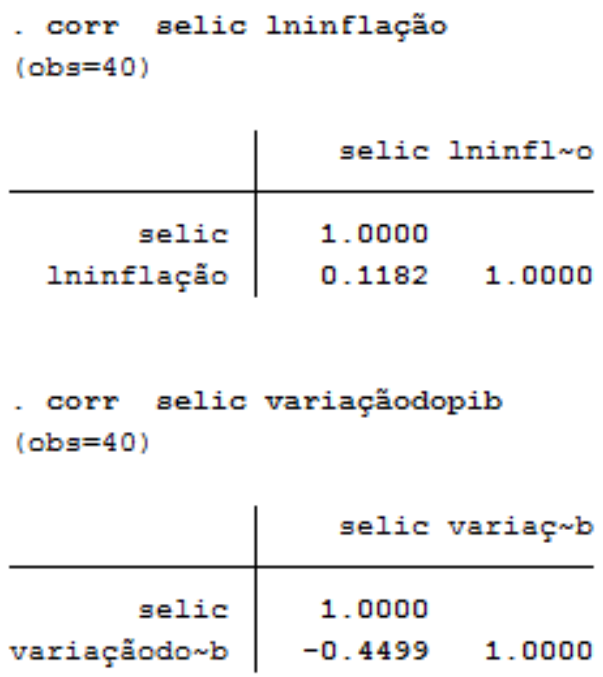

Fonte: Resultados da pesquisa.

Verifica-se que os resultados do coeficiente de correlação de Pearson encontram-se no intervalo entre 0,00 e 0,30, para a relação entre taxa SELIC e a inflação, apontando, portanto, uma fraca correlação linear positiva, e entre -0,30 e -,0,60 para taxa SELIC e a variação trimestral do PIB, apontando, portanto, uma moderada correlação linear negativa. 


\section{pontěditora}

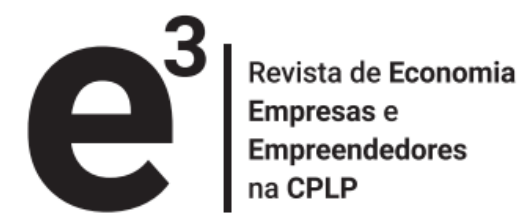

\section{CONSIDERAÇÕES FINAIS}

O objetivo deste trabalho foi analisar a correlação entre a taxa de juros básica da economia brasileira (SELIC), com o nível da atividade económica do país (PIB), e com a inflação (IPCA). Assim, buscou-se responder se existe uma relação entre mudanças na taxa básica de juros sobre a inflação e o PIB, bem como o grau dessa relação.

As políticas monetárias são de bastante importância para o crescimento e controlo de uma economia. Por isso, é importante que as autoridades monetárias façam escolhas com bastante cautela para que o retorno dela seja benéfico para a economia. Uma dessas políticas monetárias usadas no Brasil este ano foi a redução da taxa base de juros, a SELIC.

As taxas praticadas no Brasil são mais altas do que as praticadas no mercado internacional, o que, para aplicações financeiras, torna-se atrativo realizar esse tipo de investimento no país. Entretanto, sabe-se que a taxa alta de juros implica a redução de investimentos privados numa economia. Com a finalidade de voltar a ter crescimento económico positivo e controlar a inflação, o BACEN anunciou algumas reduções na taxa de juros no período de estudo, ou seja, nos últimos 10 anos.

Visto isso, buscamos analisar o comportamento da taxa de juros, do crescimento económico e da inflação ao longo dos últimos 10 anos, a fim de verificar como foi a relação dessas variáveis e se uma politica monetária expansionista seria uma medida eficaz para a economia brasileira.

A partir da correlação linear de Pearson, o presente estudo verificou que existe uma moderada correlação negativa entre a taxa de juros e o crescimento económico, o que mostra que a política aplicada pode responder de forma positiva na economia. Ou seja, taxas de juros menores estão relacionadas com o crescimento na atividade produtiva. Entretanto, existem outras variáveis que afetam o PIB de uma forma mais importante, como por exemplo, o consumo das famílias.

Já para a inflação, o resultado obtido foi de que existe uma fraca correlação entre ela e a taxa de juros, pressupondo que mudanças na taxa de juros têm pouca influência sobre a inflação. Logo, pode-se pressupor que uma política de diminuição de taxa de 


\section{pontěditora}

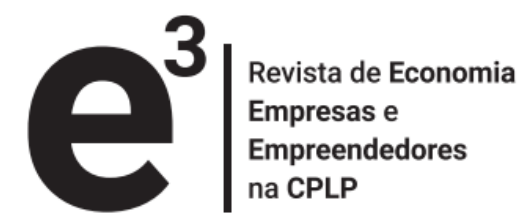

juros vai afetar o nível de inflação de maneira menos eficaz do que o seu efeito sobre o PIB, como comentado anteriormente.

Notamos, a partir dos dados coletados, uma variação com picos para a inflação, pois existem períodos do ano onde factores exógenos afetam a produção e realização de bens e serviços. No caso do PIB, verificámos que nos últimos três anos a variação ficou sempre negativa, o que pode ser considerado uma recessão da atividade económica. Para os dados referentes à taxa de juros, verifica-se uma variação senoidal.

Desta forma, conclui-se que a atividade económica do país, ou seja, o PIB teve uma melhor resposta com a redução da taxa de juros, do que a inflação.

\section{Agradecimentos}

Agradecemos á Prof., M. $^{a}$ Gisele de Cássia Gusmão pela orientação e apoio na elaboração deste trabalho.

\section{REFERÊNCIAS}

ALMEIDA A. C. S; LEITE, K. V. B. Aspectos Políticos e Teóricos da Relação entre Taxa de Juros, Inflação e Déficit Público, 2009.

BRASIL. Banco Central do Brasil. Disponível em:<http://www.bcb.gov.br>. Acesso em 10 março de 2017.

BRASIL. Dados Diários da Selic. Disponível em:

$\langle$ http://www.bcb.gov.br/htms/selic/selicdiarios.asp $\rangle$. Acesso em: 26/03/2017.

BRASIL: IBGE. Instituto Brasileiro de Geografia e Estatística. Disponível em: <http://www.ibge.gov.br>. Acesso em 10 Março de 2017.

BRASIL.Índices de Preços no Brasil. Disponível em:

$<$ http://www.bcb.gov.br/conteudo/homeptbr/FAQs/FAQ\%2002\%C3\%8Dndices\%20de\%20Pre\%C3\%A7os\%20no\%20Brasil.pf >. Acesso em: 19/04/2017.

BRASIL: IPEADATA. Índice de Preço ao Consumidor Amplo (IPCA). Disponível em: 〈http://www.ipeadata.gov.br/>. Acesso em: 20/03/2017. 


\section{pontěditora}

BRASIL. Notas da 203 ${ }^{a}$ Reunião do Comitê de Política Monetária (Copom) do Banco Central do Brasil. Disponível em: <http://www.bcb.gov.br/htms/copom/not20161130203.pdf > . Acesso em: 19/04/2017.

CAETANO, S.M.; CORREA, W.L.R.; SILVA JR, G.E. Abordagem discreta para a dinâmica da taxa Selic-meta, 2011.

CARRARA, A. F.; CORREA, A.L. O regime de metas de inflação no Brasil: uma análise empírica do IPCA, 2012.

D.OMAR, J.H. Taxa de juros: comportamento, determinação e implicações para a economia brasileira, 2008.

GUJARATI, D. N. Econometria Básica. Rio de Janeiro: Elsevier, 2006.

MENDONÇA, H.F.; DEZORDI, L. L. e CURADO, M. L. A determinação da taxa de juros em uma economia sob metas para inflação: o caso brasileiro. Porto Alegre, 2005.

MENDONÇA, H. F. Metas para inflação e taxa de juros no Brasil: uma análise do efeito dos preços livres e administrados, 2007.

OREIRO, J. L; PAULA, L. F; SILVA, G. J. C; AMARAL, R. Q. Por que as taxas de juros são tão elevadas no Brasil? Uma avaliação empírica, 2012.

SANTOS, A. R. Metodologia científica: a construção do conhecimento. Rio de Janeiro: DP \& A, 1999.

BRASIL: IBGE. Tabelas Completas. Disponível em:

<http://www.ibge.gov.br/home/estatistica/indicadores/pib/defaultcnt.shtm $>$. Acesso em: 13/03/2017.

\section{(cc) BY-NC-SA}

O trabalho $\mathrm{e}^{3}$ - Revista de Economia, Empresas e Empreendedores na CPLP está licenciado com uma Licença Creative Commons - Atribuição-NãoComercial-Compartilhalgual 4.0 Internacional. 